\title{
Safety Risk Evaluation of Large and Complex Bridges during Construction Based on the Delphi-Improved FAHP-Factor Analysis Method
}

\author{
Teng Ji, ${ }^{1}$ Ji-Wei Liu, ${ }^{1}$ and Qing-Fu Li ${ }^{2}{ }^{2}$ \\ ${ }^{1}$ Powerchina Roadbridge Group Co., Ltd., Beijing 100048, China \\ ${ }^{2}$ School of Water Conservancy Engineering Zhengzhou University, Zhengzhou 450001, China \\ Correspondence should be addressed to Qing-Fu Li; lqflch@zzu.edu.cn
}

Received 19 October 2021; Revised 13 January 2022; Accepted 17 January 2022; Published 23 February 2022

Academic Editor: Milos Knezevic

Copyright ( $) 2022$ Teng Ji et al. This is an open access article distributed under the Creative Commons Attribution License, which permits unrestricted use, distribution, and reproduction in any medium, provided the original work is properly cited.

\begin{abstract}
With the increase in construction scale and difficulty of large and complex bridges in China, it has become increasingly difficult to assess the safety risks of bridges during the construction period. Therefore, how to reasonably assess the safety risk of large, complex bridges during construction has become particularly important. Existing assessment methods are subjective in assigning weights, and it is difficult to select representative important factors to focus on for the prevention and control of numerous risk sources; they do not comprehensively consider the correlation of various risk sources during the construction period. To address the above shortcomings, a safety risk assessment of large and complex bridges during the construction period based on the Delphiimproved fuzzy analytic hierarchy process (FAHP) factor analysis method is proposed in this paper. First, the Delphi method was used to conduct a general survey of safety risk factors during the bridge construction period, and then the work breakdown structure-risk substructure (WBS-RBS) was used to establish the evaluation index system. Second, the improved FAHP was combined with it to calculate the weight of each risk factor. Finally, the factor analysis method was used to determine the correlation degree of each risk factor, and representative factors were selected to express the risk degree of the object to be evaluated to screen out major risk factors in the construction process. Finally, the feasibility and practicality of the method are verified by combining an actual engineering case with AHP (analytic hierarchy process) to perform a comparative study, which provides a reference basis for subsequent bridge construction risk prevention.
\end{abstract}

\section{Introduction}

In recent years, as China's demand for transport infrastructure has increased, the construction of bridges in China has accelerated accordingly, and construction locations have gradually shifted from mountainous to coastal areas. The construction of large and complex bridges in coastal areas is characterized by high construction difficulty, long construction times, and many uncontrollable factors. Because it involves marine operations, the building of these bridges leads to innovation in construction methods; coupled with the complex and changing environment of coastal areas, the construction conditions are harsher than in other environments, leading to greater difficulty in the construction of complex bridges. Therefore, the dangers of the constructing complex bridges in coastal areas are greatly increased. Some scholars have pointed out that the risks faced by structures such as bridges during the construction period are much higher than those during the operational period $[1,2]$. In addition, due to the influence of factors such as geology, hydrology, and construction complexity, bridge construction safety accidents occur frequently in China, resulting in very large numbers of casualties and a very large amount of property losses, as well as adverse effects on society. For example, according to the analysis of 84 collapse accidents of various engineering structures in the United States from 1977 to 1981, 21 of them occurred during the construction period, accounting for $25 \%$ of the total. Further, more than two-thirds of bridge collapse accidents that occurred in China from 1984 to 1988 occurred during the construction 
period. This shows that there is a high risk during the construction of bridges, which must be given sufficient attention. Therefore, to ensure the quality of bridge construction and the safety of the construction process, it is necessary to analyze and study the safety risks during the bridge construction period and to correct and prevent the construction process and management steps with potential safety hazards to ensure the construction quality and safety. For example, adverse factors such as ship collisions, sea breezes, surge tide pressure, and deep marine accumulation of soft ground foundations exist.

Today, the domestic and international research on the construction period safety risk assessment of complex bridges in coastal areas is still in its infancy, and both theoretical research and practical application still need to be expanded. There are many risk factors in the construction period of complex bridges in coastal areas; for example, given adverse factors such as ship collisions, sea breeze, surge tide pressure, and deep marine accumulation of soft ground foundations, each factor is interrelated and dependent on each other, and the threat of hidden risk factors to the construction period is no less than that of explicit risk factors. The scientific identification method and evaluation analysis method are the basis of controlling the safety risk during the construction period. The main methods commonly used for risk evaluation are Monte Carlo simulation analysis [3], analytic hierarchy process (AHP) [4], Technique for Order Preference by Similarity to an Ideal Solution (TOPSIS) method [5], machine learning method [6, 7], triangular fuzzy number (TFN) and the AHP [8]. The idea of risk analysis originated in France and was first used in the insurance industry; in the 1950s, risk management was established as a separate discipline in the face of the threat of the nuclear industry. Risk analysis encompasses the risk assessment of things, and conducting safety risk assessment is beneficial in understanding the risk state of the structure and identifying specific risk source factors. A number of scholars have conducted studies on the safety risk assessment of large and complex bridges during the construction period. Peng [9] applied the integrated hierarchical analysis method and cloud model to propose a cluster decisionmaking method of cloud clustering to determine the main risk factors and risk losses by means of expert scoring and applied the cloud generator to calculate the numerical features of expert scoring to quantitatively assess bridge safety risks. Gong [10] summarized the risk factors for the bridge construction period, which are divided into internal factors, external factors, and human factors. Internal factors mainly include internal action, material properties, and geometric parameters, external factors include external temporary supports, natural climate, and external loads, and human factors mainly include management, design, construction, modeling, and statistics. Different factors will have different consequences according to their degree of influence, and when several risk factors cross each other, the probability of risk is greatly increased. Lai et al. [11] used the likelihood, exposure, criticality (LEC) method to select the potential risk, risk conditions, and triggers of the bridge structure construction period as risk indicators to calculate the weights, used gray correlation theory to evaluate the risk in terms of risk occurrence probability and loss, and ranked the risk sources according to their indicators in order of merit to determine significant risk sources. The levels of risks at all levels were clarified, and the empirical study showed that the method effectively improved the evaluation accuracy of the evaluation model. Liu [12] applied a fuzzy comprehensive evaluation model to evaluate bridge construction safety risks based on the study of advanced risk management at home and abroad. Liu [13] combined the ant colony algorithm and BP neural network to optimize the model of the BP neural network for bridge construction period risk by using the ant colony algorithm. Yang et al. [14] established an assessment model based on extended belief rule base (EBRB) joint optimization for bridge risk assessment. The work first proposed the generation method and the approximate reduction method of the extended belief rule by introducing parameter optimization and data envelopment analysis, respectively; then, the joint optimization method of EBRB was proposed based on iterative optimization by linking these two methods together to ensure that the constructed EBRB has the optimal parameter values and number of parameters. Finally, the validity of the proposed model was tested by introducing a recognized dataset commonly used in the field of bridge risk assessment. The results showed that the proposed model can significantly improve the accuracy of bridge risk assessment. Khan et al. [15] proposed a framework for assessing bridge fire risk. Within this framework, each criterion, subcriterion, and alternative that may affect bridge fire risk is assigned a weight value based on its importance. Using AHP to determine the weights of different factors and validating the analysis with examples, the method can estimate the fire risk of a specific bridge in a region or the entire bridge network, which can help in the prevention and control of bridge risks. Regarding risk assessment models, Stewart [16] assessed the reliability of bridges based on risk levels and environmental analysis, which provides a better assessment model for the structural inspection of bridges. Yang et al. [17] developed a new disjunctive belief rule-based (DBRB) expert system for bridge risk assessment that takes BRB into account as a type of belief rule-based (BRB) system, thus overcoming the most common conjunctive belief rules (CBR) consisting of a BRB expert system with a combinatorial explosion problem. With the proposed dynamic parameter optimization model and improved differential evolution (IDE) algorithm, the DBRB expert system is complete and can obtain globally optimal parameter values for modeling bridge risks compared to the existing CBR and DBR-related parameter optimization models. Andric and Lu [18] combined fuzzy hierarchical analysis with fuzzy logic to propose a basic framework for bridge risk assessment and showed that both models can be effective in achieving bridge risk assessment.

Scientific assessment methods are an important part of safety risk evaluation and measure the accuracy of risk analysis. Although many scholars have conducted many theoretical and applied studies on bridge risk assessment, there are few studies on safety risk assessment during the construction period, which is much riskier than other 
periods. In addition, existing studies have not considered the identification of dynamic risk sources as the most fundamental part of risk assessment, which is not conducive to reflecting the potential risk factors for bridge projects, and the assessment methods used are more subjective in assigning weights. It is difficult to select representative and important factors to focus on prevention and control for many risk sources without considering the correlation among risk sources during the construction period. The premise of risk assessment is identifying risk sources; however, there are many dynamic risk sources in the construction process that are gradually generated during the construction process. Some evaluation indices in the bridge construction process are fuzzy, and when using hierarchical analysis to determine the weight of the indices, the relative importance of each index cannot be determined at all. Factor analysis explains the meaning of each factor by using the idea of dimensionality reduction to study the interrelationships among many variables, find the truly correlated variables, and divide the variables with high correlation into one category, each of which represents a common factor. Its main function is to simplify the data, explain the relationship between the original variables, and emphasize the correlation between the variables. It is suitable for selecting representative factors from many risk factor indicators to express the degree of risk of the object to be evaluated. For large and complex bridge construction projects in coastal areas, it is difficult to conduct an accurate analysis using the existing risk assessment methods. Through an in-depth study of the special environment of coastal areas and the construction characteristics of large and complex bridges, this paper establishes a comprehensive analysis method based on the existing evaluation and analysis, including the Delphi method, improved FAHP, and factor analysis, and applies it to the analysis of safety risks during the construction period of large and complex bridges in coastal areas, taking the premise of risk source identification combined with the Delphi method for initial screening of risk sources and using improved FAHP for weight calculation of risk factors to reduce the influence of human subjective factors on weight values. Finally, the correlation between risk factors was analyzed using the factor analysis method, and construction projects with higher risk coefficients were determined, which improved the comprehensiveness and accuracy of the evaluation process.

The main contributions of this paper are as follows:

(i) The Delphi method and improved FAHP were used to identify and calculate the weight of risk sources during the construction period of large and complex bridges. By establishing a census list of risk sources and combining the Delphi method, the risk sources are scored, and the risk sources generated during the whole construction process can be considered.

(ii) The factor analysis method was proposed to assess the safety risks during the bridge construction period, and the factors with higher comparative risk levels were screened out, taking the correlation between the risk factors into full consideration. (iii) The rationality and feasibility of the Delphi-improved FAHP factor analysis method were applied and studied on actual engineering cases, and a comparative study with AHP was performed to verify the applicability of the method, which provides a reference for the safety risk assessment of similar large and complex bridges during the construction period.

The rest of this paper is summarized as follows. Section 2 describes the methods used for safety risk evaluation during bridge construction and their risk identification process. Section 3 presents an applied study of the methods used in this paper with practical cases. Conclusions are given and discussed in Section 4. Figure 1 is a flowchart of the method used in this paper.

\section{Identification Process and Methods}

2.1. Identification of Risk Sources during Bridge Construction. There are many risk sources in the construction period of large and complex bridges, which are closely related to each other. The application of reasonable methods for screening can ensure the accuracy, scientific design, and effectiveness of construction safety risk assessment. These risk factors include the complex and not clear geological and hydrological environment in which the bridge is located, and foundation of the construction plan often has to change and replace the construction equipment due to sudden changes in geology and hydrology. The bridge foundation structure not only needs to bear the effect of large vertical loads, but also needs to directly bear the effect of large horizontal loads such as wind and waves, water currents, and ice pressure and faces greater risks in construction of bridges in coastal areas, as the construction conditions are more complicated. On the one hand, due to the large scope of the project itself, material supply, operating sites, and other factors and a wide range of construction vessels, it is easy to experience difficulties in the organization of the construction site. On the other hand, offshore construction is more affected by cold currents, waves, high winds, and other hydrological and meteorological influences, and risk events such as concrete pouring of bearing platforms and superstructure construction are increased. The main methods of risk identification mainly include expert scoring methods and checklist methods. However, due to the lengthy construction period and complex process of bridge construction, the potential risk sources are not static as the construction process gradually completes the bridge superstructure, substructure, bearings, and other structures. There will be dynamic risk sources, and so the above method for identification is more difficult, and it is difficult to exhaustively identify the risk sources. The Delphi method can concentrate the rich engineering experience of experts and thus effectively identify risks [19]. WBS-RBS was originally proposed by David Hilson, a leader in the field of PMI in the U.S. The basic principle is to decompose the risk source into two parts: the work breakdown structure (WBS) and the risk breakdown structure (RBS). When using the WBS-RBS system, it is 


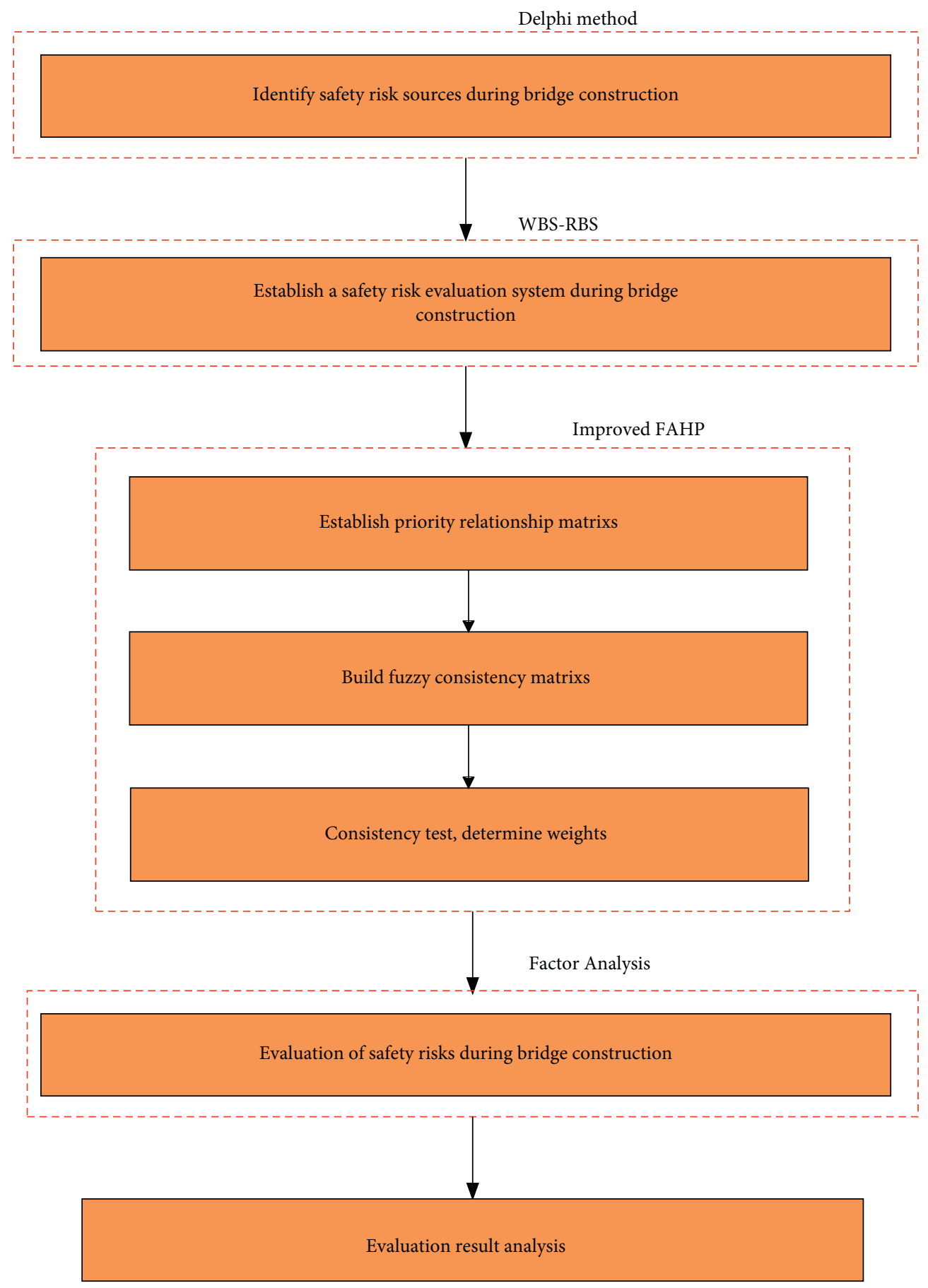

FIgURE 1: Flow chart of the method used in this paper.

possible to analyze any of the risk factors present in the construction process. In the lower part of the system, the work is further divided into more independent parts, called work units, which are theoretically more conducive to the analysis of subprojects. WBS-RBS is an engineering risk identification method that can be used to discern the overall picture of an engineering project but can also go into the specific details of engineering construction [20]. Based on these factors, this paper uses the Delphi method to identify risk sources and determines the main risk sources through expert assignment. Then, using WBS-RBS, each process is decomposed and analyzed to identify the risk sources level by level to achieve the purpose of risk source identification.

\subsubsection{Decomposition Structure of Bridge Construction} Technology. The construction technology decomposition of large and complex bridges in coastal areas should consider not only the construction sequence, but also the formation mechanism of risk sources. Bridge engineering is a bottomup structural system that includes the structural characteristics and construction sequences of bridges. Bridge 
construction technology can be divided into foundation engineering, temporary engineering, tower column engineering, and beam slab engineering. The construction procedures for large and complex bridges are shown in Figure 2.

The risks of subprojects should be considered for specific project capacity and enter into the next level of project division, as shown by Table 1 . When users decompose the construction process for other types of bridges, the analysis should be carried out in conjunction with the construction process of the bridge itself. For example, simply supported beam bridges can be divided into lower engineering, upper engineering, and auxiliary engineering.

\subsubsection{Decomposition Structure of Bridge Construction} Technology. Different scholars use different risk classifications according to the characteristics of risk formation. Combined with the environmental characteristics of coastal areas, the division of safety risk factors for large and complex bridge construction should follow the principle of easy risk identification. Combined with the theory of system safety engineering and bridge construction engineering, the Delphi method was used to invite 15 experts from different fields, and after the experts' opinions about the classification of bridge construction risk factors were obtained, they were collated, summarized, counted, and anonymously fed back to each expert, and opinions were again sought, concentrated, and fed back, until a unanimous opinion was obtained. The expert questionnaire is shown in Table 2. When users conduct a survey of safety risk sources during the construction period of other types of bridges, the survey should be carried out in conjunction with the specific construction processes of the bridge; for example, the possible risk sources for the lower engineering of simply supported beam bridges are pile foundation construction, reinforcement cage tying, and welding.

Finally, the bridge construction risk factors can be divided into four types of risk sources: human, machine, material, and environment, thus dividing the bridge construction risk source system into four subsystems, human, machine, material, and environment, and establishing a WBS decomposition tree, where WBS refers to the identification of bridge construction risk sources as a general objective and is then decomposed into multiple independent units. The decomposition diagram is shown in Figure 3. Users can directly refer to the WBS decomposition tree based on the four categories of risk sources: human, machine, material, and environment.

Human factor risk refers to a source of risk from human error. The construction of the whole bridge project is a process that is dominated by people, mainly performing surveys, measurements, designs, construction, management, detection, and maintenance. Therefore, human error has the greatest impact on the entire bridge project.

Machine factor risk refers to the source of risk caused by mechanical failure. Mechanical failures include mechanical loss, mechanical aging, mechanical failure, mechanical mismatch, and insufficient mechanical production capacity.
For large bridge construction, human power is limited, and machinery is required to assist the construction. The quality of machinery directly determines the occurrence rate of safety incidents.

Material factor risk refers to the risk source formed by material factors. The materials here do not only refer to the reinforcement, cement, sand and gravel, asphalt, etc., required for the construction of bridges, but also include the temporary materials used, such as hanging baskets, grouting machines, supports, welds, cutting devices, and various kinds of spammers and other application tools. Materials are the pillars of the project, which directly affects the quality of the project. With the continuous innovation of the bridge structure situation and span, new materials and new technologies are always emerging for engineering applications. Therefore, the influence of the quality of materials in the construction process is becoming increasingly obvious.

Environmental factor risk refers to the risk source formed by environmental factors. Environmental risk sources include the natural environment and construction environment. The natural environment refers to the wind, rain, lightning, temperature, humidity, earthquakes, volcanoes, tsunamis, etc., at the project location. The construction environment refers to the convenience conditions that can be provided for construction based on existing technical conditions and capital level. All kinds of environmental factors in construction can affect the safety risk.

There are many risk factors in the construction period of large and complex bridges in coastal areas, and their influence degrees are different. The reasonable division of risk sources is an important part of safety risk assessment. Therefore, continuing to use the Delphi method, inviting experts from construction units, supervision units, design units, etc., and considering the four aspects of human, machine, material, and environment can determine the risk events that each risk source subsystem has. The results of the are expressed using RBS, where RBS refers to the decomposition of the four main factors of bridge construction safety risk into individual basic events. At this time, WBS is combined to obtain the factors affecting the risk sources of the bridge construction period, and the final results are shown in Table 3. The specific risk [11] sources of various risk factors are shown in Table 2. Users can create an RBS based on the division of risk events in the four areas of people, machines, materials, and environment that different types of bridges have during construction.

\subsubsection{Identification of Risk Sources during Bridge} Construction. Combined with the construction process breakdown structure table and the risk sources of various risk factors, the project is reviewed item by item. First, the risk checklist, as shown in Table 4, is sent to the relevant technical personnel, including the main project leader, project construction personnel, project supervision personnel, experts, and scholars related to the project and public officials, for scoring and assignment. If more than $93 \%$ of the requested data are collected, the data source is considered 


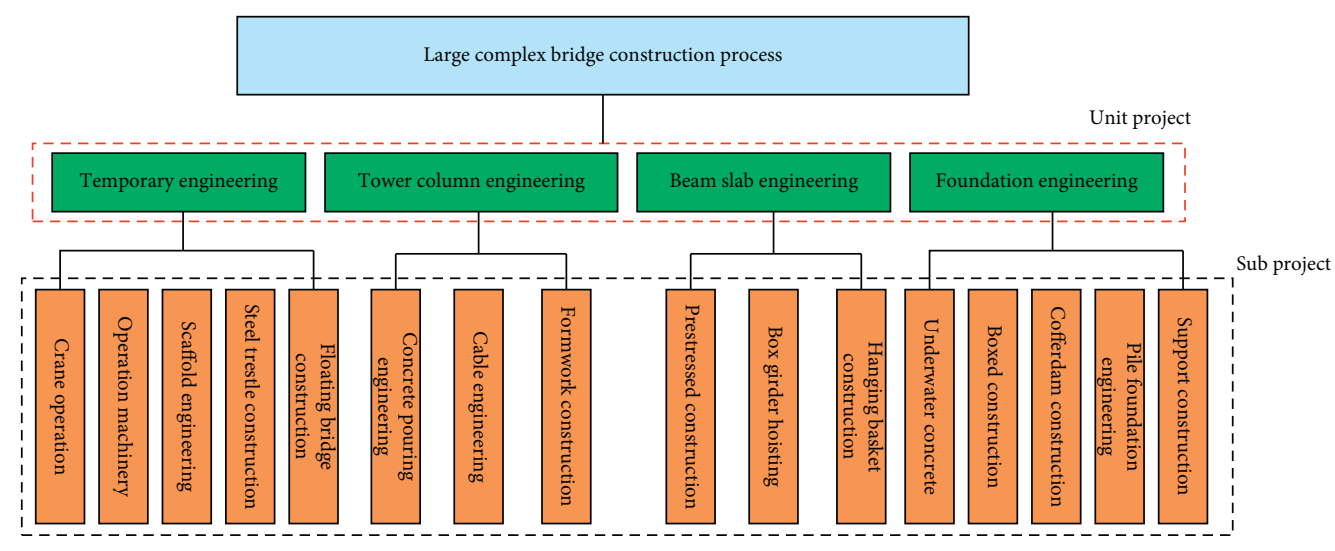

FIGURE 2: Organizational chart of construction procedures for large and complex bridges.

TABLE 1: Decomposition of the large complex bridge construction process.

\begin{tabular}{lc}
\hline Unit project & Subproject \\
\hline Foundation engineering $a_{1}$ & $\begin{array}{c}\text { Support construction } a_{11} \text {, pile foundation engineering } a_{12} \text {, cofferdam construction } a_{13}, \\
\text { boxed construction } a_{14} \text {, underwater concrete } a_{15}\end{array}$ \\
$\begin{array}{c}\text { Temporary engineering } a_{2} \\
\text { Tower column engineering } a_{3}\end{array}$ & $\begin{array}{c}\text { Foating bridge construction } a_{21} \text {, steel trestle construction } a_{22} \text {, scaffold engineering } a_{23}, \\
\text { operation machinery } a_{24}, \text { crane operation } a_{25}\end{array}$ \\
Beam slab engineering $a_{4}$ & Formwork construction $a_{31}$, cable engineering $a_{32}$, concrete pouring engineering $a_{33}$ \\
\hline
\end{tabular}

TABLE 2: Questionnaire on safety risk sources during bridge construction.

\begin{tabular}{|c|c|c|c|c|c|c|c|}
\hline \multirow[b]{2}{*}{ Project } & \multicolumn{4}{|c|}{ Risk sources } & \multirow[b]{2}{*}{$\begin{array}{c}\text { Harmful } \\
\text { consequences }\end{array}$} & \multirow[b]{2}{*}{$\begin{array}{l}\text { Level of risk (please compare } \\
\text { and quantify two by two) }\end{array}$} & \multirow[b]{2}{*}{ Remarks } \\
\hline & Human factor & Machine factor & Material factor & $\begin{array}{l}\text { Environmental } \\
\text { factor }\end{array}$ & & & \\
\hline$\cdots$ & $\cdots$ & $\cdots$ & $\cdots$ & $\cdots$ & $\cdots$ & $\cdots$ & $\cdots$ \\
\hline$\cdots$ & $\cdots$ & $\cdots$ & $\cdots$ & $\cdots$ & $\cdots$ & $\cdots$ & $\cdots$ \\
\hline $\begin{array}{l}\ldots \\
\text { Filler. }\end{array}$ & $\cdots$ & $\cdots$ & Proofreader: & eader. ${ }^{\cdots}$ & \multicolumn{3}{|c|}{ Date of filling out the form: } \\
\hline
\end{tabular}

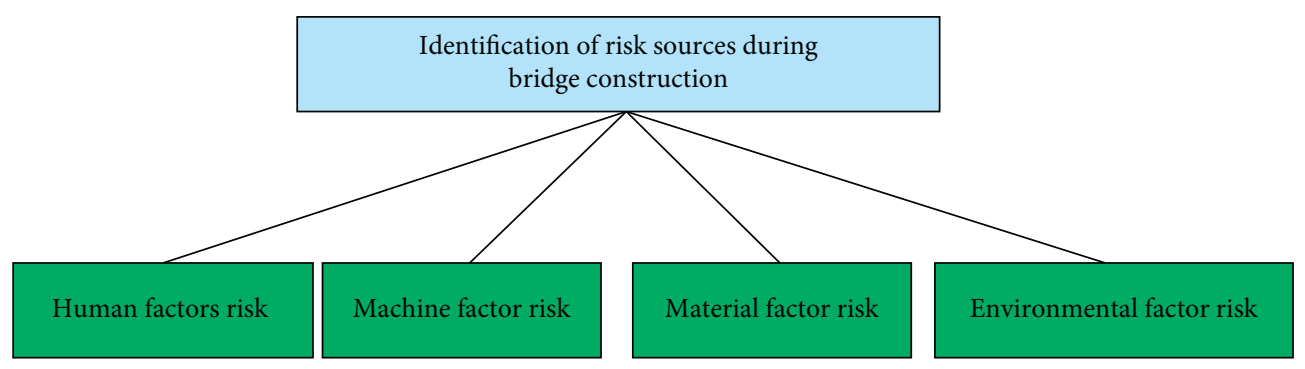

FIGURE 3: WBS decomposition of risk sources during bridge construction.

TABLE 3: Construction risk factor decomposition.

\begin{tabular}{lc}
\hline Risk factor & Subproject \\
\hline Human risk $b_{1}$ & Personnel operation error $b_{11}$, human design error $b_{12}$, inexperience of personnel $b_{13}$ \\
Machine risk $b_{2}$ & Device not running $b_{21}$, equipment mismatch $b_{22}$ \\
Material risk $b_{3}$ & Insufficient material strength $b_{31}$, defective materials $b_{32}$, materials expired $b_{33}$ \\
Environmental risk $b_{4}$ & Tsunami disaster $b_{41}$, typhoon $b_{42}$, heavy rain $b_{43}$, earthquake disaster $b_{44}$ \\
\hline
\end{tabular}

reliable, and the construction safety risk source data are sorted out, which require further analysis. After performing the previous task, when determining the unique construction technology of other types of bridges and the safety risk sources during the construction period, users should develop a general survey table for the safety risk 
TABLE 4: Survey on safety risk sources of bridge construction.

\begin{tabular}{|c|c|c|c|c|c|c|}
\hline \multirow{2}{*}{ Project } & \multirow{2}{*}{ Risk sources } & \multirow[b]{2}{*}{$b_{11}$} & \multicolumn{2}{|c|}{$b_{1}$} & \multirow{2}{*}{\multicolumn{2}{|c|}{$\begin{array}{l}b_{2} \\
b_{21}\end{array}$}} \\
\hline & & & $b_{12}$ & $b_{13}$ & & \\
\hline \multirow{4}{*}{$a_{1}$} & $a_{11}$ & $\checkmark$ & $x$ & $x$ & $\ldots$ & $\checkmark$ \\
\hline & $a_{12}$ & & & & & \\
\hline & $a_{13}$ & & & & & \\
\hline & $\ldots$ & & & & & \\
\hline$a_{2}$ & $a_{21}$ & & & & & \\
\hline$\ldots$ & $\ldots$ & & & & & \\
\hline
\end{tabular}

sources of the bridge during the construction period and lay the foundation for the subsequent weight assignment.

2.2. Risk Source Weight Assignment. The improved FAHP is adapted from AHP. By introducing the theory of fuzzy mathematics, the consistency test problem in AHP is solved. The fuzzy judgment matrix in this method conforms to people's thinking and logic, and the form is simple and accurate. AHP is a combined qualitative and quantitative method proposed by Professor Saaty in the US in the 1970s. The method is a decision-making tool for complex systems, which mainly involves constructing a judgment matrix, comparing the relative importance in each level, calculating the relative weight of each item in that level, and finally combining the relative weights of each level [21]. AHP does not require a large amount of data and can quantify some qualitative issues through the scoring of experts. The method does not take into account the dynamics of decision-makers in a dynamic environment, so it is difficult to express objectivity in the evaluation results; therefore, some scholars have combined fuzzy mathematics and hierarchical analysis methods to form a new decision-making method, FAHP [22]. FAHP is a new method of risk assessment formed by combining fuzzy analysis with hierarchical analysis. When using AHP, it is difficult to maintain consistency in ways of thinking when there are many indicators at different levels, and fuzzy hierarchical analysis can solve this problem by introducing the "affiliation degree" in fuzzy mathematics [23] and using the affiliation function for the indicators with a fuzzy nature (see Table 5).

In general, the improved FAHP method has the following advantages over AHP:

(1) Simple in theory. The FAHP method is simple to calculate during the process of determining weights and only needs to build a comparison matrix between two and two, without a complicated calculation process, which is convenient for decisionmakers to operate.

(2) Strong engineering applicability. FAHP can be analyzed from both qualitative and quantitative aspects. As a huge decision system, engineering needs a combination of qualitative understanding and quantitative description to fully interpret all its information, and the method is widely used in engineering practice.

(3) Good overall performance. When using FAHP for analysis, the whole problem is first regarded as a system, and the purpose of decision-making as a whole is achieved by analyzing each part of the system, which can be applied to the decision-making problems of complex systems.

2.3. Improved FAHP. After the risk sources are identified, they need to be categorized and analyzed, such as what risk sources are involved in the foundation project and what are the risk events; we rely on the WBS-RBS to gradually expand these risks by level, which involves the allocation problem. At this time, we need to listen to expert opinions regarding the bridge construction of each structure in the human, machine, and material ring, which may provide the risk sources according to the Delphi method to enumerate and combine with the actual construction of the project. The division is carried out according to the Delphi method, taking into account the actual construction characteristics of the project and listening to the experts' opinions. Then, values are assigned to the identified risk sources. The method of assignment is based on the possibility of risk sources, the controllable degree of risk sources, the maturity of construction technology, and the frequency of risk sources through the Delphi method. Combined with the judgment ideas of AHP [24], it is more flexible and convenient to assign the weight of risk sources.

The improved FAHP mainly establishes the comparison matrix of assessment indices by comparing the relative importance of risk source factors, constructs the fuzzy consistency judgment matrix of assessment indices, calculates the weight vector of assessment indices, and then conducts risk evaluation and analysis of bridges. The user needs to compare the risk sources of other types of bridges during the construction period and determine the relative importance of the risk source factors to establish a comparison matrix of evaluation indicators. The subsequent weight calculation can be calculated according to the following calculation formula, and the parameters involved in each step formula are explained.

2.3.1. Fuzzy Evaluation. The traditional fuzzy analytic hierarchy process (FAHP) evaluation concept is rough, as follows:

$$
\begin{cases}b_{i}>b_{j}, & b_{i j}=1, \\ b_{i}=b_{j}, & b_{i j}=0.5, \\ b_{i}<b_{j}, & b_{i j}=0 .\end{cases}
$$


TABLE 5: Scale values of membership.

\begin{tabular}{lcc}
\hline Scaling & Definition & Explanation \\
\hline 0.5 & Equally important & Element $i$ has the same importance compared to element $j$ \\
0.6 & Slightly more important & Element $i$ is slightly more important than element $j$ \\
0.7 & Obviously important & More important \\
0.8 & Extremely important & Element $i$ is significantly more important than element $j$ \\
0.9 & Inverse comparison & Element $i$ is much more important than element $j$ \\
$0.1,0.2,0.3,0.4$ & Element $i$ is extremely more important than element $j$ \\
& The result of comparing the importance of element $i$ over element $j$ is $b_{i j} ;$ \\
\hline
\end{tabular}

The evaluation steps of the improved FAHP are similar to those of the fuzzy chromatography analysis method. First, according to the scoring situation of experts, the data are sorted out and processed to improve the rationality of the evaluation standard [25]. Compared with the traditional evaluation concept, it is humanized and conforms to the logical thinking mode of human beings. The traditional expert scoring comparison method uses the 1-9 scale method [26], while Table 1 shows that the distribution of the affiliation function is 0 to 1 to ensure that the overall affiliation interval is 0 to 1 . Therefore, the refinement process of the severity level and the possibility level is realized by linear interpolation, which refines these two levels from 1 scale to the 0 to 1 scale, and this shift can effectively improve the calculation accuracy and unify the interval variables for special bridge construction. The stability and reliability of the risk level estimation results are guaranteed [27]. The expert scoring processing is shown in

$$
b_{j}=\frac{\sum_{i=1}^{n} V_{i j}}{n \cdot 100}, \quad j=1,2, \ldots m,
$$

where $b_{j}$ is the $j$-th risk source scoring value after data processing, and $V_{i j}$ is the actual scoring value of the $i$-th expert for the $j$-th risk source. In addition, 100 is the percentage scalar.

2.3.2. Establish a Priority Relation Matrix. The priority relation matrix compares the risk sources of the same type, judges the risk degree of each risk source, and determines the overall weight coefficient according to the lower-level risk matrix. The length of the $b_{i j}$ interval is 2 , and the median value is 0 . According to the mapping principle, $b_{i j}$ is converted into the value of the $0-1$ interval, and 0.5 is taken as the median value of the interval. The changed form is as follows:

$$
\begin{aligned}
& b_{i j}=b_{i}-b_{j}, \\
& b_{i j}^{*}=\frac{b_{i j}}{2}+0.5,
\end{aligned}
$$

where $b_{i j}$ is the difference between Row $i$ and Column $j$, and $b_{i j}^{*}$ is the comparison value after the change.

\subsubsection{Establishing Fuzzy Consistent Matrix $R$ and Relative} Weight. According to equations (2)-(4), the fuzzy consistent matrix $R$ is established.

$$
\begin{aligned}
R_{i j} & =\frac{k_{i}-k_{j}}{2 n}+0.5, \\
k_{i} & =\sum_{j=1}^{n} b_{i j}, \quad i=1,2, \ldots, n .
\end{aligned}
$$

The elements in the fuzzy consistent judgment matrix $R$ are added in rows to obtain vector $c$, and the vector $c$ is normalized to obtain the relative weight $w$ [28].

$$
\begin{aligned}
& c_{i}=\sum_{j=1}^{n} R_{i j}, \quad i=1,2, \ldots, n, \\
& w_{i}=\frac{c_{i}}{\sum_{k=1}^{n} c_{k}}, \quad i=1,2, \ldots, n .
\end{aligned}
$$

2.4. Factor Analysis Method. The bridge construction process is a dynamic system. Through construction process decomposition and project risk factor decomposition, the risk source identification method shows that the same risk source does not exist solely in a fixed project process, but that risk sources may be related and influenced by each other. If only the identified risk sources are controlled, the management method will be too mechanical and will play an ineffective role in risk control. Therefore, the factor analysis method is used to conduct microanalysis on the obtained risk sources. By combining the occurrence mechanism of risk sources and internal complex internal relations, the correlation degree of various risk sources was evaluated to determine the major risk sources [29]. The user can perform the corresponding calculations by the following calculation steps and formulas to obtain the evaluation results, where the parameters involved in each step are explained. 


\section{(1) Principle of factor analysis}

First, the variables are standardized, so that the mean value of each variable is 0 , and the standard deviation is 1 . Then, the original variable is represented by a linear combination of $k(k<p)$ factors $f_{k}[30]$, namely,

$$
\begin{aligned}
& \left\{\begin{array}{l}
x_{1}=a_{11} f_{1}+a_{12} f_{2}+\ldots+a_{1 k} f_{k}+\varepsilon_{1}, \\
x_{2}=a_{21} f_{1}+a_{22} f_{2}+\ldots+a_{2 k} f_{k}+\varepsilon_{2}, \\
\ldots, \\
x_{p}=a_{p 1} f_{1}+a_{p 2} f_{2}+\ldots+a_{p k} f_{k}+\varepsilon_{p},
\end{array}\right. \\
& x=a f+\varepsilon, \\
& h_{i}^{2}=\sum_{j=1}^{k} a_{i j}^{2}, \\
& s_{i}=\sum_{j=1}^{p} a_{i j}^{2} .
\end{aligned}
$$

(2) BM SPSS statistics V21.0 software was used to solve and process the data, and the feasibility of the method was determined by means of factor extraction, consistency analysis, and construction validity analysis [31]. Finally, the factor score is calculated according to equation (13), and the safety risk of large and complex bridges in coastal areas during the construction period is quantitatively evaluated.

$$
\begin{aligned}
& F=a_{1} f_{1}+a_{2} f_{2}+\ldots+a_{n} f_{n}, \\
& f=\sum_{i=1}^{v} v q .
\end{aligned}
$$

(3) In particular, $a$ is the factor contribution rate, $f$ is the factor score coefficient, $n$ is the number of factors, the maximum eigenvalue method is selected for the number of factors, the factor has an eigenvalue greater than $1, v$ is the number of original factors, and $q$ is the factor weight in the factor score matrix.

\section{Engineering Application}

3.1. Engineering Background. The Zhongkai expressway is an east-west expressway planned by Zhongshan City, Jiangmen City, Guangdong Province connecting Hong Kong and Macao, Shenzhen, Zhongshan, Jiangmen main city, Kaiping City and Taishan City, of which Yinzhou Lake Bridge is a control node project of Zhongshan Kaiping expressway, whose geographical location is Sanjiang Town, Jiangmen City, Guangdong Province, spanning Shazai Island, Tanjiang River, and connecting with Shuangshui Town. Its main channel bridge includes a double tower and double cable plane hybrid composite beam cable-stayed bridge with a semifloating system. The span combination is $56.8+64.8+66.4+530+66.4+64.8+56.8 \mathrm{~m}$, and the total length of the main bridge is $903 \mathrm{~m}$, the total width of the main beam top is $36 \mathrm{~m}$, the mid-span is a PK box composite beam, and the side span is a concrete beam. The cable tower is an A-type bridge tower, and the auxiliary pier and transition pier are box-type piers.

The lower part of the bridge structure has a box-type thin-walled pier and column foundation pier with a bored pile foundation. The main pier is arranged with $36 \Phi 2.8 \mathrm{~m}$ bored piles, $53 \mathrm{~m}$ long on the east side, and $67 \mathrm{~m}$ long on the west side; $13 \Phi 2.2 \mathrm{~m}$ bored piles, $54 \mathrm{~m}$ and $55 \mathrm{~m}$ long on the east auxiliary pier; $2 \times 6 \Phi 2.2 \mathrm{~m}$ bored piles, $70 \mathrm{~m}$ and $58 \mathrm{~m}$ long on the west auxiliary pier; $13 \Phi 2.2 \mathrm{~m}$ bored piles, $62 \mathrm{~m}$ long on the east transition pier; and $13 \Phi 2.2 \mathrm{~m}$ bored piles, $49 \mathrm{~m}$ long on the west transition pier. The tower bearing platform is $60.1 \mathrm{~m}$ in the cross-bridge direction and $22.4 \mathrm{~m}$ in the along-bridge direction, with a thickness of $7 \mathrm{~m}$ and a tower height of $2.5 \mathrm{~m}$; the bearing platform of the east side transition pier, auxiliary pier, and west side transition pier adopts an integral-type bearing platform, and the left and right side bearing platforms are connected with cross-ties, such that each bearing platform has a plan size of $13.6 \mathrm{~m} \times 9 \mathrm{~m}$ and a thickness of $3.5 \mathrm{~m}$; the bearing platform of the west side auxiliary pier adopts a separation-type bearing platform. The west side auxiliary pier bearing adopts a separated bearing, with a plane size of $13.6 \mathrm{~m} \times 9 \mathrm{~m}$ and a thickness of $3.5 \mathrm{~m}$.

3.2. Risk Source Identification. The WBS-RBS method was used to establish a specific risk source index system, and then the Delphi method was used to score the participating experts to identify the safety risk sources of the construction of the lower part of the Yinzhou Lake Bridge. The risk source identification table established by the WBS-RBS method is shown in Table 6. The scoring data of 15 experts are processed by equation (2). The final construction safety risk identification of the lower part of the Yinzhou Lake Bridge is shown in Table 7.

3.2.1. Establish a Priority Relation Matrix. Taking $D_{12}$, fire prevention on-site, as an example, the priority relationship matrix between $D_{12}$ E is established by applying the improved fuzzy analytic hierarchy process (FAHP) theory, combined with the site construction situation and expert scoring value, as shown in Table 8.

According to equations (2)-(8), the fuzzy consistent matrix and relative weight of $D_{12}-E$ are calculated. The results are shown in Table 9.

3.2.2. Total Weight of the Fuzzy Hierarchy. The above methods were applied to solve the priority relationship matrix and to calculate the relative weights for $A_{11}-D_{12}$, which will not be repeated herein. Finally, the fuzzy hierarchical relative weight matrix $w$ was established for the construction risks of the lower part of the Yinzhou Lake Bridge to determine the importance of each risk factor to the construction process. 
TABLE 6: Risk source identification table established using the WBS-RBS method.

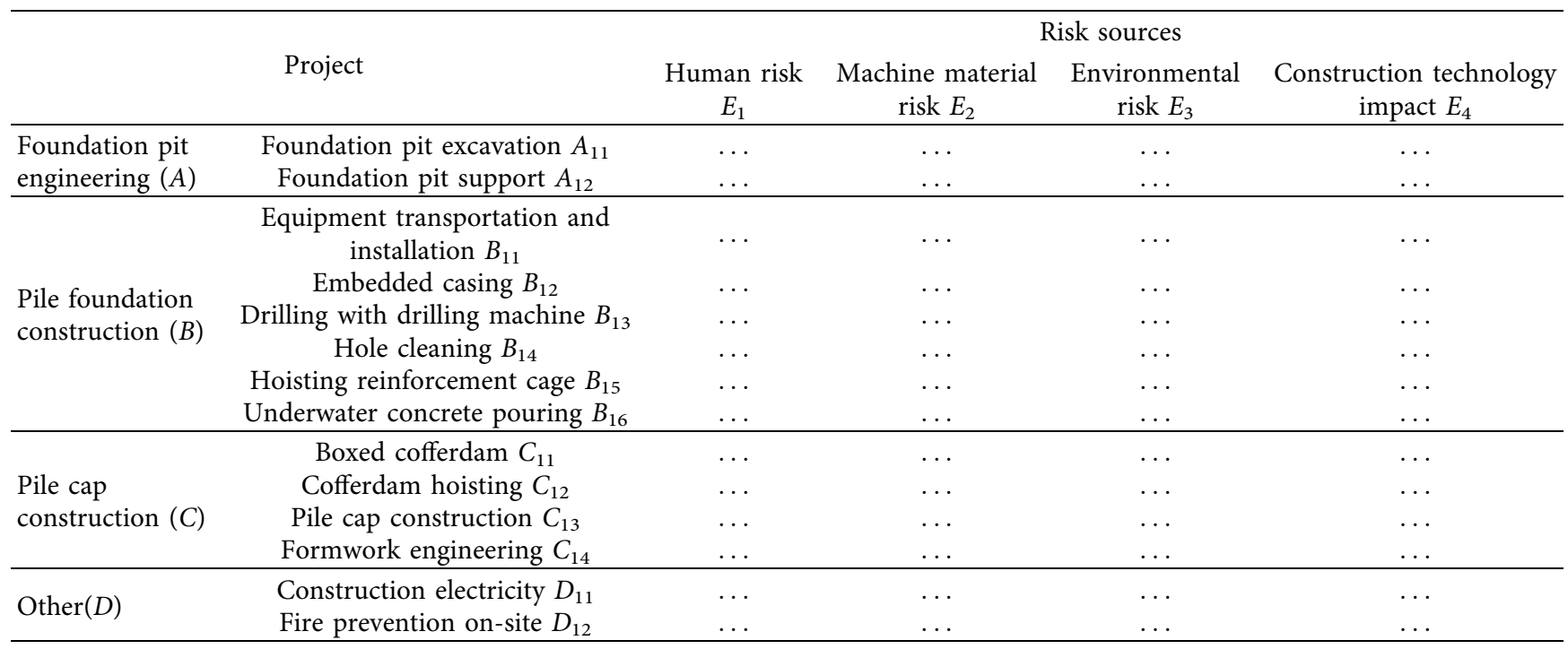

TABLE 7: Risk source score table for the lower part of the Yinzhou lake bridge.

\begin{tabular}{|c|c|c|c|c|c|}
\hline \multicolumn{2}{|c|}{ Project } & \multicolumn{4}{|c|}{ Risk sources } \\
\hline & & $E_{1}$ & $E_{2}$ & $E_{3}$ & $E_{4}$ \\
\hline \multirow{2}{*}{$A$} & $A_{11}$ & 0.791 & 0.701 & 0.705 & 0.734 \\
\hline & $A_{12}$ & 0.789 & 0.776 & 0.746 & 0.697 \\
\hline \multirow{6}{*}{$B$} & $B_{11}$ & 0.703 & 0.832 & 0.607 & 0.612 \\
\hline & $B_{12}$ & 0.817 & 0.822 & 0.714 & 0.734 \\
\hline & $B_{13}$ & 0.748 & 0.737 & 0.694 & 0.735 \\
\hline & $B_{14}$ & 0.797 & 0.767 & 0.714 & 0.742 \\
\hline & $B_{15}$ & 0.784 & 0.801 & 0.718 & 0.780 \\
\hline & $B_{16}$ & 0.894 & 0.815 & 0.698 & 0.795 \\
\hline \multirow{4}{*}{ C } & $C_{11}$ & 0.795 & 0.795 & 0.707 & 0.749 \\
\hline & $C_{12}$ & 0.800 & 0.749 & 0.701 & 0.735 \\
\hline & $C_{13}$ & 0.797 & 0.782 & 0.732 & 0.793 \\
\hline & $C_{14}$ & 0.816 & 0.816 & 0.750 & 0.841 \\
\hline \multirow{2}{*}{$D$} & $D_{11}$ & 0.807 & 0.831 & 0.790 & 0.840 \\
\hline & $D_{12}$ & 0.755 & 0.809 & 0.689 & 0.801 \\
\hline
\end{tabular}

TABLE 8: $D_{12}-E$ priority relationship matrix.

\begin{tabular}{lcccc}
\hline$D_{12}$ & $E_{1}$ & $E_{2}$ & $E_{3}$ & $E_{4}$ \\
\hline$E_{1}$ & 0.500 & 0.546 & 0.602 & 0.541 \\
$E_{2}$ & 0.454 & 0.500 & 0.556 & 0.495 \\
$E_{3}$ & 0.398 & 0.444 & 0.500 & 0.439 \\
$E_{4}$ & 0.459 & 0.505 & 0.561 & 0.500 \\
\hline
\end{tabular}

TABLe 9: $D_{12}-E$ fuzzy consistent matrix and relative weight.

\begin{tabular}{lcccrr}
\hline$D_{12}$ & $E_{1}$ & $E_{2}$ & $E_{3}$ & $E_{4}$ & $W_{1}$ \\
\hline$E_{1}$ & 0.500 & 0.523 & 0.551 & 0.521 & 0.498 \\
$E_{2}$ & 0.477 & 0.500 & 0.528 & 0.470 & 0.250 \\
$E_{3}$ & 0.449 & 0.472 & 0.500 & 0.236 \\
$E_{4}$ & 0.480 & 0.503 & 0.531 & 0.500 & 0.252 \\
\hline
\end{tabular}




$$
W=\left[\begin{array}{llllllllllllll}
0.257 & 0.255 & 0.252 & 0.256 & 0.252 & 0.255 & 0.252 & 0.262 & 0.254 & 0.257 & 0.253 & 0.251 & 0.249 & 0.249 \\
0.246 & 0.253 & 0.268 & 0.256 & 0.251 & 0.252 & 0.254 & 0.252 & 0.254 & 0.250 & 0.251 & 0.251 & 0.252 & 0.256 \\
0.246 & 0.249 & 0.240 & 0.243 & 0.246 & 0.245 & 0.243 & 0.237 & 0.243 & 0.244 & 0.244 & 0.243 & 0.247 & 0.241 \\
0.251 & 0.243 & 0.240 & 0.245 & 0.251 & 0.248 & 0.251 & 0.249 & 0.248 & 0.249 & 0.252 & 0.254 & 0.253 & 0.255
\end{array}\right]^{T}
$$

3.3. Risk Assessment and Analysis. The internal relationship between risk sources and engineering projects is determined with the factor analysis method, and the relative weight $W$ calculated by the fuzzy hierarchy is imported into IBM SPSS for factor analysis and calculation.

3.3.1. Data Analysis. The variance contribution rate of factors is calculated with software, as shown in Table 10. Among them, the first set of data describes the initial solution of the factor, the characteristic root of the first factor is 1.773 , the explained total variance of the original four variables is $44.335 \%$, and the cumulative variance contribution rate is $44.335 \%$; the ending mode of the second and third factors is similar to that of the first factor; the third group of data describes the factor solution, with a total variance of $99.877 \%$, which indicates that the three factors reflect $99.877 \%$ of the information of the original variable.

Figure 4 shows that the first factor has the highest eigenvalue and largest contribution rate to the variable interpretation, while the eigenvalue of the third factor is smaller, therefore contributing less to the explanatory variables, and they can be ignored.

3.3.2. Factor Score. Table 11 is the factor score matrix, and the factor score function can be calculated according to the regression algorithm. According to equations (10)-(11), the final score of the factors is calculated and sorted. The data results are shown in Table 12.

3.3.3. Result Analysis. According to the fuzzy comprehensive calculation method, the foundation excavation factor score is 0.83 , ranking the first, and the risk coefficient is the largest; the score of the foundation pit support factor is 0.55 , ranking the second, with the same risk; the score of the hole cleaning work factor after drilling is 0.33 , which is slightly lower than the first two construction procedures, but there are also greater risks; the other construction processes are also high. The factor scores and the risk order of the project are shown in Table 13. During the construction progress of the project, according to the known risk coefficient, scientific management methods are applied to pay attention to the construction process with high risk and take reasonable construction measures to avoid risks in time and reduce economic losses.

The main purpose of bridge construction safety risk identification and analysis is to perform better risk management and control to ensure the safety of people and structures during bridge construction. This process requires reasonable risk response measures, scientific risk management measures that are the key to risk disposal, consideration that different sizes of risk disposal programs are not the same, and the requirement of scientific consideration that is not arbitrary, which requires compliance with certain principles. The specific principles of risk response strategies are as follows.

\section{(i) Availability and validity}

Risk control should pay attention to the availability of control methods, and the methods should be combined with the practical factors of the situation to ensure that they are available in engineering practice. The risk decision should be made according to the characteristics of the risk occurrence. At the same time, the effectiveness of the control method should be ensured, and the proposed risk control method should be able to prevent and control the risk effectively.

(ii) Cost reasonableness

The bridge construction process has many kinds of risks and great difficulty in prevention, which causes the cost of the control process to also be larger. Therefore, in the process of risk control, the issue of cost should be considered, the size of the cost and benefit should be compared, and the funds should be reasonably controlled to ensure that the premise of solving the risk is to try to save costs and balance the gains and losses.

(iii) Comprehensiveness

Bridge construction projects are large and complex systems, and construction processes face numerous risks. Each risk control program has its own uniqueness and limitations. The control process should be considered cross-use to ensure that the control scope and control benefits are maximized.

(iv) Science

The selection of a risk control program should have a scientific basis and not be a blind decision. The risk identification and assessment of the entire bridge are rigorously scientifically proven, thus ensuring the accuracy of risk recognition.

3.4. Risk Assessment and Analysis. The most commonly used method for risk assessment is the AHP method [32, 33], which we adopted as a comparative study. The main steps of the AHP method are establishing a hierarchical structure model, constructing all judgment matrices in each level, using the two-by-two comparison method to derive the weights of individual influencing factors, and ranking the weights of each influencing factor. 
TABLE 10: Total variance explained.

\begin{tabular}{lccccccccc}
\hline \multirow{2}{*}{ Component } & \multicolumn{3}{c}{ Initial eigenvalues } & \multicolumn{3}{c}{ Extraction sums of squared loadings } & \multicolumn{2}{c}{ Rotation sums of squared loadings } \\
& Total & \% of variance & Cumulative \% & Total & \% of variance & Cumulative \% & Total & \% of variance & Cumulative \% \\
\hline 1 & 1.773 & 44.335 & 44.335 & 1.773 & 44.335 & 44.335 & 1.759 & 43.980 \\
2 & 1.243 & 31.081 & 75.416 & 1.243 & 31.081 & 75.416 & 1.257 & 31.437 \\
3 & 0.978 & 24.461 & 99.877 & & & & & 73.980 \\
4 & 0.005 & 0.123 & 100.000 & & & & & \\
\hline
\end{tabular}

Extraction method: principal component analysis.

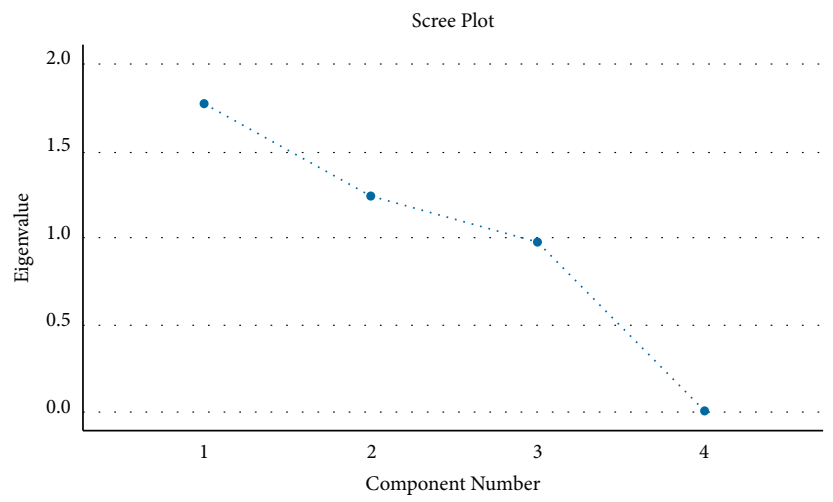

FIgURE 4: Factor eigenvalue distribution.

TABle 11: Component score coefficient matrix.

\begin{tabular}{lcc}
\hline & \multicolumn{3}{c}{ Component } \\
& 1 & 2 \\
\hline Risk sources 1 & -0.031 & 0.787 \\
Risk sources 2 & -0.539 & -0.350 \\
Risk sources 3 & 0.320 & -0.147 \\
Risk sources 4 & 0.420 & -0.187 \\
\hline
\end{tabular}

TABLE 12: Factor score table.

\begin{tabular}{lcc}
\hline Project name & Factor score & Sequence \\
\hline$A_{11}$ & 0.83 & 1 \\
$A_{12}$ & 0.55 & 2 \\
$B_{11}$ & -1.12 & 13 \\
$B_{12}$ & 0.16 & 4 \\
$B_{13}$ & -0.27 & 12 \\
$B_{14}$ & 0.33 & 3 \\
$B_{15}$ & 0.03 & 9 \\
$B_{16}$ & -0.2 & 11 \\
$C_{11}$ & 0.12 & 5 \\
$C_{12}$ & 0.07 & 7 \\
$C_{13}$ & 0.05 & 8 \\
$C_{14}$ & -0.53 & 14 \\
$D_{11}$ & 0.11 & 6 \\
$D_{12}$ & -0.12 & 10 \\
\hline
\end{tabular}

3.4.1. Building Hierarchical Structure Model. The hierarchical structure diagram is generally divided into 3 layers, the top layer, middle layer, and bottom layer, representing the target layer, criterion layer, and indicator layer, respectively. In actual case analysis, the structure can be divided according to the objectives to be evaluated, the factors to be considered and the interrelationship points among
TABLE 13: Scale of proportions.

\begin{tabular}{lc}
\hline $\begin{array}{l}\text { The relative importance of the } i \text {-th risk event } \\
\text { over the } j \text {-th risk event }\end{array}$ & $\begin{array}{c}\text { Quantified } \\
\text { values }\end{array}$ \\
\hline Equally important & 1 \\
Slightly more important & 3 \\
Stronger and more important & 5 \\
Strongly important & 7 \\
Extremely important & 9 \\
Intermediate value of two adjacent judgments & $2,4,6,8$ \\
\hline
\end{tabular}

evaluation indicators. According to on-site research, literature review, and expert opinion, it was determined that the risk source engineering items of the lower part of the Yinzhou Lake Bridge are foundation pit engineering, pile foundation engineering, bearing platform construction, and others, and each risk source engineering item contains multiple risk factors. Finally, a three-layer hierarchical structure model containing the target layer, criterion layer, and indicator layer is established. As shown in Figure 5, A, B, C, $\mathrm{D}$ and $A_{11}, A_{12}, \ldots, D_{12}$ refer to risk source engineering projects and risk source factors, respectively; the details are the same as those in Table 6 for risk events and risk source designations.

3.4.2. Construction of Judgment Matrix at Each Layer. By inviting experts such as construction experts and supervision experts, the relative importance of the two factors is calibrated using a scale of proportionality, as shown in Table 13, and the judgment matrix of risk source factors at the criterion level relative to the target level is shown in Table 14. 


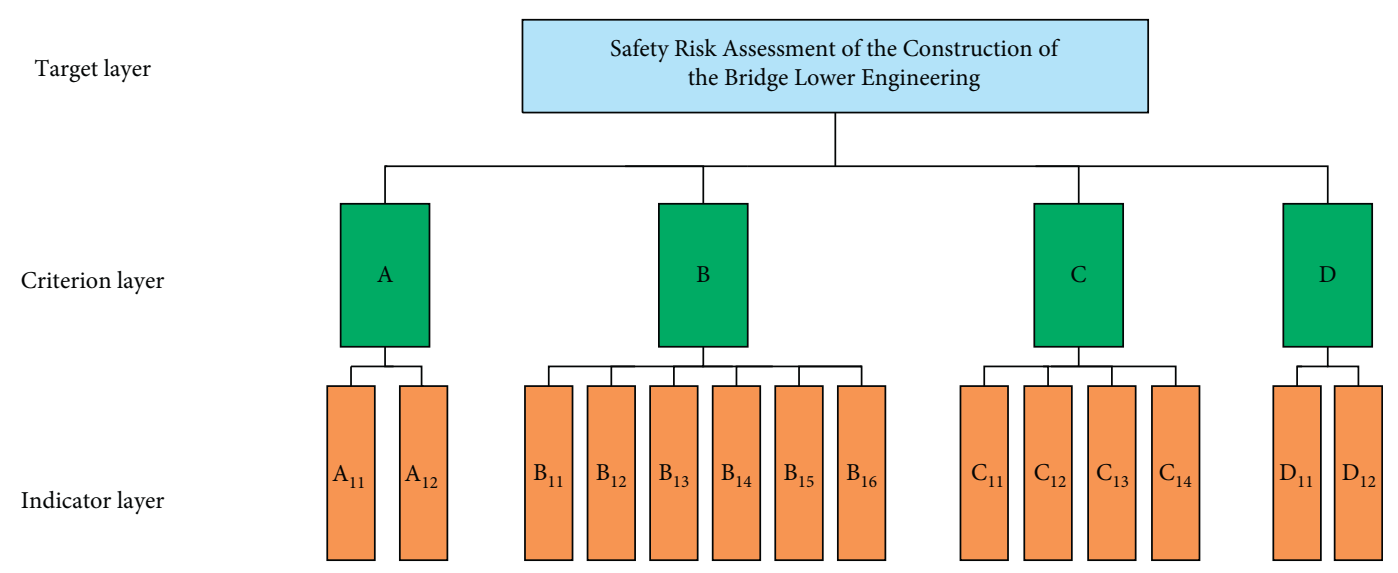

FIgURE 5: The hierarchical structure model of the safety risk assessment of the project under the pile of the Yinzhou lake bridge.

TABLE 14: Judgment matrix of the objective layer-criterion layer.

\begin{tabular}{ccccc}
\hline & $A$ & $B$ & $C$ & $D$ \\
\hline$A$ & 1 & 3 & 5 & 7 \\
$B$ & $1 / 3$ & 1 & 5 & 3 \\
$C$ & $1 / 5$ & $1 / 5$ & 1 & $1 / 3$ \\
$D$ & $1 / 7$ & $1 / 3$ & 3 & 1 \\
\hline
\end{tabular}

To ensure that the results obtained with this method are reasonable and reliable, it is necessary to judge the consistency of the target layer-criterion layer judgment matrix. The consistency check is shown in

$$
C R=\frac{C I}{R I}<0.1
$$

where $R I$ is the average random consistency index. The equation for $C I$ is $C I=\lambda_{\max }-n / n-1, n$ is the order of the judgment matrix, $R I$ takes the values shown in Table 15 , and $\lambda_{\max }$ is the maximum eigenvalue.

The square root method is adopted to find the solution of $\lambda_{\max }$ [34] as follows: Step one: multiply each element by row to obtain $u_{i j}$; see equation (13); Step 2: raise $u_{i j}$ to the power of $n$ to obtain $u_{i}$; see equation (15); Step 3: normalize $u_{i}$ to obtain the weight vector $\omega_{i}$; see equation (16); Step 4: calculate the maximum characteristic root $\lambda_{\max }$ of the judgment matrix; see equation (17).

$$
\begin{aligned}
u_{i j} & =\prod_{j=1}^{n} b_{i j}, \\
u_{i} & =\sqrt[n]{u_{i j}}, \\
\omega_{i} & =\frac{u_{i}}{\sum_{i=1}^{n} u_{i}}, \\
\lambda_{\max } & =\sum_{i=1}^{n} \frac{(A \omega)_{i}}{n \omega_{i}},
\end{aligned}
$$

where $b_{i j}$ is the relative importance value of the $i$-th evaluation index relative to the $j$-th evaluation index, which is the value in the judgment matrix; $A$ is the judgment matrix; $\omega$ is the eigenvector; and $n$ is the number of elements. In this
TABle 15: Average random consistency index.

\begin{tabular}{ccccccccc}
\hline 1 & 2 & 3 & 4 & 5 & 6 & 7 & 8 & 9 \\
\hline 0.00 & 0.00 & 0.58 & 0.9 & 1.12 & 1.24 & 1.32 & 1.41 & 1.45 \\
\hline
\end{tabular}

case, the maximum eigenvalue of $\mathrm{CI}$ is 4.235 , $\mathrm{RI}$ is 0.078 , and $\mathrm{CR}$ is 0.9 . Therefore, since $0.087<0.1$, the consistency requirement is satisfied. The weight vector occupied by $A-D$ is $w=(0.566,0.265,0.060,0.109)$.

The following is the judgment matrix of each factor in the index layer relative to the criterion layer. The relative importance of each factor in the index layer to the criterion layer is calculated by two comparisons, and the results are shown in Tables 16-19.

According to the calculation method of the weight feature vector of each evaluation factor in the criterion layer relative to the target layer, the weight vector of the judgment matrix of $\mathrm{A}-\mathrm{A}_{1-2}$ is obtained, and it is calculated that $\lambda_{\text {max }}=2, C I=0, R I=0$, and $C R=0<0.1$, which meets the consistency requirement. The weight vector occupied by $A$ $A_{1-2}$ is $w=(0.750,0.250)$.

The same calculation method is used to obtain the weight vector of the judgment matrix of $B-B_{1-6}$, and it is calculated that $\lambda_{\max }=6.563, C I=0.113, R I=1.24$, and $C R=0.091<0.1$, which satisfies the consistency requirement. The weight vector occupied by $B-B_{1-6}$ is $w=(0.157$, $0.398,0.055,0.240,0.119,0.031)$.

In the same way, the weight vector of the judgment matrix $C-C_{1-4}$ is obtained, and after calculation, $\lambda_{\max }=4.076, C I=0.025, R I=0.9$, and $C R=0.028<0.1$, which meets the consistency requirements. The weight vector occupied by $C-C_{1-4}$ is $w=(0.543,0.254,0.085,0.119)$.

The same calculation method is used to obtain the weight vector of the judgment matrix of $D-D_{1-2}$, and it is calculated that $\lambda_{\max }=2, C I=0, R I=0$, and $C R=0<0.1$, which also meets the consistency requirements. The weight vector occupied by $D-D_{1-2}=(0.750,0.250)$.

3.4.3. Calculation of Combination Weights and Total Hierarchical Ranking. The combined weight of each risk source is the product of the weight of each risk source in the 
TABle 16: $A-A_{1-2}$ judgment matrix.

\begin{tabular}{lcc}
\hline$A$ & $A_{1}$ & $A_{2}$ \\
\hline$A_{1}$ & 1 & 3 \\
$A_{2}$ & $1 / 3$ & 1 \\
\hline
\end{tabular}

TABLe 17: $B-B_{1-6}$ judgment matrix.

\begin{tabular}{ccccccc}
\hline$B$ & $B_{1}$ & $B_{2}$ & $B_{3}$ & $B_{4}$ & $B_{5}$ & $B_{6}$ \\
\hline$B_{1}$ & 1 & $1 / 3$ & 3 & $1 / 3$ & 3 & 5 \\
$B_{2}$ & 3 & 1 & 7 & 3 & 3 & 7 \\
$B_{3}$ & $1 / 3$ & $1 / 7$ & 1 & $1 / 3$ & $1 / 5$ & 3 \\
$B_{4}$ & 3 & $1 / 3$ & 3 & 1 & 3 & 7 \\
$B_{5}$ & $1 / 3$ & $1 / 3$ & 5 & $1 / 3$ & 1 & 5 \\
$B_{6}$ & $1 / 5$ & $1 / 7$ & $1 / 3$ & $1 / 7$ & $1 / 2$ & 1 \\
\hline
\end{tabular}

TABle 18: $C-C_{1-4}$ judgment matrix.

\begin{tabular}{lcccc}
\hline$C$ & $C_{11}$ & $C_{12}$ & $C_{13}$ & $C_{14}$ \\
\hline$C_{11}$ & 1 & 3 & 3 & 7 \\
$C_{12}$ & $1 / 3$ & 1 & 3 & 3 \\
$C_{13}$ & $1 / 3$ & $1 / 3$ & 1 & $1 / 3$ \\
$C_{14}$ & $1 / 7$ & $1 / 3$ & 3 & 1 \\
\hline
\end{tabular}

TABle 19: $D-D_{1-2}$ judgment matrix.

\begin{tabular}{lcc}
\hline$D$ & $D_{1}$ & $D_{2}$ \\
\hline$D_{1}$ & 1 & 3 \\
$D_{2}$ & $1 / 3$ & 1 \\
\hline
\end{tabular}

indicator layer and the feature vector of the weight of the indicator layer. Then, the calculated weight of each risk source index was sorted from large to small, and the results are shown in Table 20.

The total ranking results of all risk factors that are involved in bridge construction were obtained as follows: foundation pit excavation $A_{11}$, foundation pit support $A_{12}$, embedded casing $B_{12}$, construction electricity $D_{11}$, hole cleaning $B_{14}$, equipment transportation and installation $B_{11}$, boxed cofferdam $C_{11}$, hoisting reinforcement cage $B_{15}$, fire prevention on-site $D_{12}$, cofferdam hoisting $C_{12}$, drilling with drilling machine $B_{13}$, underwater concrete pouring $B_{16}$, formwork engineering $C_{14}$, and pile cap construction $C_{13}$.

Comparing the improved fuzzy hierarchical factor analysis method with the AHP method in the bridge construction safety risk evaluation study, we can see that both of them use the expert scoring method to determine the relative importance of the risk sources. However, for the initial identification of risk sources, this paper adopts the fuzzy hierarchical analysis method, which can solve the problem of fuzzy evaluation indices in the bridge construction process by introducing an "affiliation degree" in fuzzy mathematics and using the affiliation function to deal with the fuzzy indices. The method proposed in this paper considers the dynamic risk sources in the construction process and selects the representative risk sources for analysis and consideration.
TABLE 20: Hierarchical total sorting results.

\begin{tabular}{lcccccc}
\hline \multicolumn{5}{c}{ Single weight } & & \\
Risk factors & $A$ & $B$ & $C$ & $D$ & Weights & Sequence \\
& 0.566 & 0.265 & 0.060 & 0.109 & & \\
\hline$A_{11}$ & 0.750 & & & & 0.4245 & 1 \\
$A_{12}$ & 0.250 & & & & 0.1415 & 2 \\
$B_{11}$ & & 0.157 & & & 0.0417 & 6 \\
$B_{12}$ & & 0.398 & & & 0.1056 & 3 \\
$B_{13}$ & & 0.055 & & & 0.0147 & 11 \\
$B_{14}$ & 0.240 & & & 0.0636 & 5 \\
$B_{15}$ & & 0.119 & & & 0.0315 & 8 \\
$B_{16}$ & & 0.031 & & & 0.0081 & 12 \\
$C_{11}$ & & & 0.543 & & 0.0326 & 7 \\
$C_{12}$ & & & 0.254 & & 0.0152 & 10 \\
$C_{13}$ & & & 0.085 & & 0.0051 & 14 \\
$C_{14}$ & & & 0.119 & 0.0071 & 13 \\
$D_{11}$ & & & & 0.750 & 0.0818 & 4 \\
$D_{12}$ & & & 0.250 & 0.0273 & 9 \\
\hline
\end{tabular}

\section{Conclusions and Discussion}

There are many risk factors present during the construction period of a large and complex bridge. In this paper, the Delphi method and WBS-RBS method are employed to identify potential dynamic risk sources, establish a safety risk evaluation index system for the construction period of a large and complex bridge, use improved fuzzy hierarchical analysis for weight calculation, and combine factor analysis to evaluate the safety risk of a large and complex bridge during the construction period. An empirical study was conducted to assess the practical application of the method, and the main conclusions are as follows.

(1) Through the construction process decomposition and construction safety factor decomposition method, a set of safety risk census systems applicable to the bridge construction period is established, which can more perfectly identify the dynamic risks in the construction process and identify them more comprehensively and accurately. Whether the results are obtained using the method proposed in this paper or the comparative study, it is concluded that foundation pit excavation and foundation pit support are relatively dangerous risk events, and so risk prevention should be strengthened in actual construction and similar projects to pay attention to these types of risk.

(2) Through the organic combination of the Delphi method, FAHP, and factor analysis method, the advantages of the above three methods are integrated to compensate for their defects. The safety risk situation of bridge construction periods is complex, and there are many uncertainties and fuzziness. This method can quantitatively analyze this kind of complex system and calculate the risk value accurately.

(3) The fuzzy comprehensive evaluation method is applied to quantitatively evaluate the safety risk of the lower part of the Yinzhou Lake Bridge during its 
construction period, and reasonable disposal measures are presented according to the risk of the project to prevent the occurrence of safety risk events and provide guidance for the safety risk assessment of the bridge construction period in the future. A comparative study was also conducted, and the scientific and accurate nature of the proposed method was fully demonstrated.

This paper provides a new method that is applicable to the evaluation of safety risks during the construction period of large and complex bridges; however, the method also has some limitations, the main 2 of which are as follows: first, the method requires the user to have a certain level of mathematical calculation ability, and the formula has some calculation complexity; second, some risk source factors may exist in the operational period or design period, and since their risk hazard levels may also be high, these factors need to be integrated with the factors of other periods. In general, as a major infrastructure country, China's infrastructure construction is accelerating, and the construction of bridges has reached new heights in terms of span, construction difficulty, and construction technology, and so traditional evaluation methods need to be innovated. Our next study will focus on the acquisition and calculation of unidentified factors, taking into account the complexity of the actual construction environment, the numerous risk sources during bridge construction, the decision to deploy these risk events, and the identification of the more important risk sources to assess their degree of risk to the overall project. For the purpose of this paper, this involves intelligent calculations, which need to rely on language programming to edit the formulas involved in these methods and transform them into source code language programs, and in practice, the user only needs to input the relevant parameters to obtain the evaluation results. To promote the use of this method, we are also strengthening it to study the risk evaluation of other types of bridges during the construction period, and we will also carry out the safety risk evaluation of other types of bridges during the construction period.

\section{Data Availability}

The data used to support the findings of this study are included within the article.

\section{Conflicts of Interest}

The authors declare that there are no conflicts of interest regarding the publication of this paper.

\section{References}

[1] T. Zayed, R. E. Minchin, and A. J. Boyd, "Model for the physical risk assessment of bridges with unknown foundation," Journal of Performance of Constructed Facilities, vol. 21, pp. 44-52, 2007.

[2] Y. Q. Xiang, Q. .Q. Wu, and T. T. Zhang, "Research on risk assessment of bridge design based on AHP-FCE model,"
China Civil Engineering Journal, vol. 43, pp. 275-280, 2010, (in Chinese).

[3] H. Naderpour, A. Kheyroddin, and S. Mortazavi, "Risk assessment in bridge construction projects in Iran using Monte Carlo simulation technique," Practice Periodical on Structural Design and Construction, vol. 24, Article ID 04019026, 2019.

[4] J. X. Xu, B. You, S. L. Shi, H. Q. Liu, and Y. Q. Zhang, "Bridge construction risk identification and assessment analysis based on analytic hierarchy process," Mining Engineering Research, vol. 35, pp. 59-64, 2020, (in Chinese).

[5] H. Wu, S. Liu, J. Wang, and T. Yang, "Construction safety risk assessment of bridges in the marine environment based on CRITIC and TOPSIS models," Journal of Coastal Research, vol. 108, pp. 206-210, 2020.

[6] W. Fan, Y. Chen, J. Li, Y. Sun, J. Feng, and P. Sareh, "Machine learning applied to the design and inspection of reinforced concrete bridges: resilient methods and emerging applications," Structures, vol. 33, pp. 3954-3963, 2021.

[7] S. Lin, S. L. Shen, A. Zhou, and Y. Xu, "Risk assessment and management of excavation system based on fuzzy set theory and machine learning methods," Automation in Construction, vol. 122, Article ID 103490, 2021.

[8] Q. Zheng, H. M. Lyu, A. Zhou, and S. Shen, "Risk assessment of geohazards along Cheng-Kun railway using fuzzy AHP incorporated into GIS," Geomatics, Natural Hazards and Risk, vol. 12, pp. 1508-1531, 2021.

[9] K. Peng, "Risk evaluation for bridge engineering based on cloud-clustering group decision method," Journal of Performance of Constructed Facilities, vol. 33, Article ID 04018105 , 2018.

[10] C. L. Gong, "Risk analysis and countermeasures for the construction of long-span cable-stayed bridges," Doctoral Dissertation, Tongji University, Shanghai, China, 2006.

[11] X. Lai, F. Wang, and Y. Tan, "Research on the construction of grey correlation risk assessment model based on bridge risk assessment," Highway Engineer, vol. 43, pp. 205-209, 2018, (in Chinese).

[12] Y. F. Liu, "Research on risk assessment methods of bridge construction," Master's thesis, Chang'an University, Xi'an, China, 2005.

[13] Q. C. Liu, "Research on safety risk assessment of bridge engineering construction," Master's thesis, Shandong University, Jinan, China, 2017.

[14] L. H. Yang, F. F. Ye, and Y. M. Wang, "Bridge risk assessment based on extended belief rule base with joint optimization," Systems engineering-theory and practice, vol. 40, pp. 1870-1881, 2020.

[15] M. A. Khan, A. A. Khan, G. A. Anwar, and A. Usmani, "Framework for fire risk assessment of bridges," Structures, vol. 33, pp. 523-532, 2021.

[16] M. G. Stewart, "Reliability-based assessment of ageing bridges using risk ranking and life cycle cost decision analyses," Reliability Engineering \& System Safety, vol. 74, pp. 263-273, 2001.

[17] H. Yang, Y. M. Wang, L. L. Chang, and Y. Fu, "A disjunctive belief rule-based expert system for bridge risk assessment with dynamic parameter optimization model," Computers \& Industrial Engineering, vol. 113, pp. 459-474, 2017.

[18] J. M. Andric and D. G. Lu, "Risk assessment of bridges under multiple hazards in operation period," Safety Science, vol. 83, pp. 80-92, 2016.

[19] A. S. Ribeiro, C. M. De, and X. Costoya, "A delphi method to classify wave energy resource for the 21 st century: application 
to the NW Iberian Peninsula," Energy, vol. 235, Article ID 121396, 2021.

[20] G. H. Chen, W. S. Wu, S. Y. Xu, and K. Liu, "HSE risk assessment of cross-sea bridge construction based on WBS-RBS and AHP," China Safety Science Journal, vol. 23, pp. 51-57, 2013.

[21] T. L. Saaty, Group Decision Making and the AHP, the Analytic Hierarchy Process, Springer Berlin Heidelberg, Berlin, Germany, 1989.

[22] F. P. Liu and J. T. Zhou, "Comprehensive evaluation of longspan bridges based on fuzzy extension analytic hierarchy process," China and Foreign Highway, vol. 35, pp. 93-99, 2015, (in Chinese).

[23] H. Qian, S. Yang, Q. Q. Peng, X.Q. Liu, and M. Chen, "Risk assessment of withstand voltage test system under high voltage based on fuzzy analytic hierarchy process," Safety and Environmental Engineering, vol. 26, pp. 111-116, 2019, (in Chinese).

[24] Y. W. Pan, J. L. Yu, and Q. Zhang, "Application of analytic hierarchy process in the selection of construction schemes for deep water caps," Construction Technology, vol. 43, pp. 72-75, 2014, (in Chinese).

[25] J. Zhang, "Research on risk analysis methods during construction of long-span bridges," Master's thesis, Tongji University, Shanghai, China, 2007.

[26] K. P. Wang, C. G. Lu, and Q. F. Li, "Study on identifying significant risk sources during bridge construction based on grey entropy correlation analysis method," Mathematical Problems in Engineering, vol. 2021, Article ID 6618039, 15 pages, 2021.

[27] W. L. Yang and Y. D. Xue, "Improved method of special risk grade estimation for highway and bridge construction," Journal of Disaster Prevention and Mitigation Engineering, vol. 35, pp. 624-629+673, 2015, (in Chinese).

[28] X. Chen, "Risk analysis of long-span suspension bridge construction," Master's thesis, Nanchang Hangkong University, Nanchang, China, 2017.

[29] Z. X. Li, "Research on risk assessment of long-span bridges in construction period," Master's thesis, Zhengzhou University, Zhengzhou, China, 2011.

[30] D. L. Feng, "Research on safety risk assessment and control of tunnel civil construction based on factor analysis-fuzzy analysis method," Master's thesis, Southwest Jiaotong University, Chengdu, China, 2013.

[31] C. B. Wang and Y. M. Song, "Research on risk factors of bridge construction based on factor analysis method," Journal of Hunan University of Arts and Science (Natural Science Edition), vol. 30, pp. 45-50, 2018, (in Chinese).

[32] A. Ghosh and R. Maiti, "Development of new ecological susceptibility index (ESI) for monitoring ecological risk of river corridor using F-AHP and AHP and its application on the Mayurakshi river of Eastern India," Ecological Informatics, vol. 63, Article ID 101318, 2021.

[33] Y. Wang, J. Liu, and T. M. S. Elhag, "An integrated AHP-DEA methodology for bridge risk assessment," Computers \& Industrial Engineering, vol. 54, pp. 513-525, 2008.

[34] Q. F. Li, H. D. Zhou, and H. Zhang, "Durability evaluation of highway tunnel lining structure based on matter element extension-simple correlation function method-cloud model: a case study," Mathematical Biosciences and Engineering, vol. 18, pp. 4027-4054, 2021. 